\title{
OBESIDADE INFANTIL: COMPREENDER PARA MELHOR INTERVIR
}

\author{
Childhood Obesity: Understanding to Better Intervene
}

La obesidad Infantil: Entender Mejor a Intervenir

\author{
LuCiana Gaudio Martins FrontZeK \\ LUANA RODRIGUES BERNARDES \\ Celina Maria Modena
}

\begin{abstract}
Resumo: O artigo visa compreender a obesidade infantil a partir de quem vivencia o fenômeno, crianças e pais, para subsidiar intervenções mais efetivas. A pesquisa foi realizada em Belo Horizonte com 10 famílias através de narrativas individuais e em grupos na perspectiva da teoria da complexidade e da fenomenologia. Com base nas narrativas foram construídas cinco categorias temáticas: o significado da comida - atrelado à visão biomédica e a elementos afetivos e psicológicos; a percepção social - predomina o olhar pejorativo; a influência do sobrepeso infantil no cotidiano - há impactos negativos nos campos físico, emocional e social; $a$ relação com profissionais da saúde - marcada por cobranças, receios e incompreensões e; motivos para não adesão ao tratamento - são implícitos e explícitos. Conclui-se que, para a compreensão da obesidade infantil e para se pensar em intervenções mais eficazes deve-se considerar o sentido atribuído à obesidade, as relações familiares, as condições socioeconômicas e todos os elementos que circundam a obesidade infantil.
\end{abstract}

Palavras-chave: Obesidade infantil; Relações familiares; Profissionais da saúde; Fenomenologia.

Abstract: The article aims to understand childhood obesity from the person who experiences, children and parents, to support effective interventions. The survey was conducted in Belo Horizonte with 10 families through individual interviews and groups from the perspective of complexity theory and phenomenology. Five thematic categories were built based on the narratives: the meaning of food - linked to the biomedical vision and the emotional and psychological elements; the social perception - a pejorative influence of childhood overweight prevails in everyday life - there are negative impacts in the fields of physical, emotional and social relationship with healthcare professionals, marked by charges, fears and misunderstandings and reasons for non-adherence to treatment - they are both implicit and explicit. We conclude that to understanding childhood obesity and to think of more effective interventions one must consider the meaning attributed to obesity, family relationships, socioeconomic conditions and all the elements that surround childhood obesity.

Keywords: Childhood obesity; Family relationships; Healthcare professionals; Phenomenology.

Resumen: El artículo tiene como objetivo comprender la obesidad infantil de la persona que la experimenta, los niños y los padres, para apoyar las intervenciones eficaces. La encuesta se llevó a cabo en Belo Horizonte con 10 familias a través de las cuentas individuales y grupos desde la perspectiva de la teoría de la complejidad y la fenomenología. Sobre la base de las narrativas fueron construidas cinco categorías temáticas; el significado de comida - ligada a la visión biomédica y los elementos emocionales y psicológicos; la percepción social - prevalece la influencia peyorativa de sobrepeso infantil en la vida cotidiana - existen impactos negativos en los campos de la relación física, emocional y social con los profesionales de la salud marcados por las cargas, los miedos y los malos entendidos y las razones de la falta de adherencia al tratamiento - ambos están implícitos y explícitos. Llegamos a la conclusión de que para la comprensión de la obesidad infantil y pensar en intervenciones más eficaces debemos tener en cuenta el significado atribuido a la obesidad, las relaciones familiares, las condiciones socioeconómicas y todos los elementos que rodean la obesidad infantil.

Palabras-clave: Obesidad infantil; Relaciones familiares; Profesionales de la salud; Fenomenología.

\section{Introdução}

A Organização Mundial da Saúde (WHO, 1998) relata crescimento da obesidade infantil em aproximadamente 40\% nos países Europeus nos últimos 10 anos. No Brasil os últimos dados fornecidos pelo Instituto Brasileiro de Geografia e Estatística (IBGE) são de 2008/2009 (Brasil, 2008). Na região sudeste o excesso de peso infantil em crianças de 5-9 anos foi de $38.8 \%$ e nas idades de 10-19 foi de 22.8\%. A Associação Brasileira para
O Estudo da Obesidade e da Síndrome Metabólica (Abeso, 2015) mantém em seu site um mapa atualizado a partir de informações oficiais, onde é possível ver por região a prevalência da obesidade.

A obesidade é considerada atualmente uma doença crônica multifatorial e assim o tratamento deve ter também uma perspectiva multidisciplinar. A obesidade evoca muitos elementos que se relacionam de forma dinâmica e simultânea, portanto qualquer tentativa fragmentada de lidar com o tema se mostrará menos eficaz. Para 
ilustrar alguns destes elementos pode-se citar: a influência midiática que estimula uma alimentação inadequada ao mesmo tempo em que se cobra um padrão ideal de magreza, a economia/política que estimula o consumismo, os interesses da indústria da alimentação não saudável, a complexidade das relações familiares envolvidas, a discriminação social sofrida, a dificuldades subjetivas de cada um, entre outros (Frontzek, 2015; Nunes, Appolinario, Abuchai \& Coutinho, 2006;).

É frequente na literatura sobre a obesidade informações sobre o aumento crescente da obesidade infantil e adulta em todo mundo, sendo considerada uma epidemia. (Freitas, 2014; Frontzek, 2015; Melo, Luft \& Meyer, 2003, Nunes, 2006,). Trata-se de um problema de saúde pública, mas também de uma questão social, já que as pessoas com sobrepeso são estigmatizadas. (Poulain, 2013). A visão da obesidade construída pela visão biomédica busca propor estratégias de controle e prevenção, através de programas prescritivos, verticais e culpabilizantes. Poulain (2013) propõe que, para serem mais efetivas as ações de prevenção nesta área deveríamos evoluir para uma lógica de responsabilidade partilhada, já que as campanhas de "combate" a obesidade extremamente prescritivas e baseadas em controle social mostram-se até mesmo contraproducentes em muitos casos. Estes dados apontam a importância de mais estudos na área.

Portanto, o objetivo desta pesquisa foi compreender a obesidade infantil pela perspectiva fenomenológica associada ao pensamento complexo para subsidiar intervenções mais efetivas, já que este ponto de vista teórico parte diretamente do fenômeno e de tudo que o envolve.

A fenomenologia em diálogo com a teoria da complexidade proposta por Morin (1996) se mostrou pertinente para a análise dos dados por apresentar uma perspectiva que abrange a complexidade dos fenômenos inter-relacionais como o é a obesidade infantil.

$\mathrm{O}$ método fenomenológico não se restringe à pesquisa qualitativa. Trata-se de um instrumento de análise lógica e de confronto à realidade. Significa uma constante indagação ao que está posto. Nesse sentido, a descrição fenomenológica poderá contar também como fonte de informação a estatística (Decastro \& Gomes, 2011). Assim a fenomenologia nos permite o movimento de ir e vir ao fenômeno. Paradoxalmente, esse movimento de ir e vir não denota instabilidade ou ausência de consistência e de rigor científico, mas um caráter de recursividade que torna o enfoque fenomenológico uma proposta de reflexão exaustiva e também uma vertente da epistemologia da complexidade de Edgar Morin (conforme citado por Ribeiro, 2015).

A complexidade por sua vez permite uma releitura crítica da prática e dos pressupostos configuradores da abordagem fragmentadora da obesidade. Nesse aspecto, ressalta-se a importância de um paradigma que se propõe a buscar o desconhecido do conhecimento pelo seu próprio inacabamento, baseando-se, por exemplo, no princípio de causalidade complexa, ou seja, causalidade mútua inter-relacionada (Morin, 1996). De forma complementar e dialógica, a ótica fenomenológica consiste em adotar uma postura de abertura e flexibilidade, desatando definições consolidadas, o que possibilita análises e resultados menos superficiais na investigação do fenômeno estudado. Husserl, precursor da fenomenologia, ergueu uma ponte entre o abismo que existia entre a ação prática da atividade científica e a natureza reflexiva da filosofia. Ele evidenciou os diferentes níveis de percepção da realidade pelo sujeito observador. Husserl nos remete a teoria da complexidade pela multiplicidade de enfoques e os questionamentos aos fundamentos da ciência (Ribeiro, 2015).

Assim, a opção de ouvir as pessoas que vivenciam cotidianamente as consequências da obesidade infantil proporciona um caminho mais próximo de suas realidades. O tema poderá ser melhor tangenciado se consideramos sua complexidade sem querer engessá-lo em conceitos previamente definidos. Desta forma, a teoria de Morin (2007) evoca a complexidade e a fenomenologia a necessidade de nos debruçarmos sobre fenômeno de maneira aberta e sem preconceitos.

No trabalho com pessoas obesas pode-se observar que é significativo a frequência com que relatam dificuldades com o peso desde a infância. É possível perceber hábitos alimentares que levam a obesidade sendo repassados por gerações (Frontzek, 2014). A seleção de alimentos é parte de um sistema comportamental complexo que na criança é determinado primeiro pelos pais (Savage, Fisher \& Birch, 2007). Diante de tantas evidências é importante refletir sobre o tema e pensar em formas efetivas de intervenção além da prevenção. Para contribuir com este objetivo foi realizada uma pesquisa em um Hospital Infantil em Belo Horizonte com famílias compostas por crianças acima do peso. Antes do trabalho de campo realizou-se uma revisão integrativa sobre a obesidade infantil (Frontzek, 2016) que apontou a percepção distorcida dos pais em relação ao sobrepeso dos seus filhos como um dos possíveis componentes para a ineficiência dos tratamentos. A literatura na área aponta que, intervenções que não envolva os pais são menos eficazes (Camargo, Azevedo \& Antonio, 2013; Melo et al, 2003).

A partir desta experiência pode-se perceber que é inviável um trabalho na área da saúde para lidar com o sobrepeso infantil que não contemple e intervenha no conjunto familiar que cerca a criança. Sendo assim, se torna necessário escutar os filhos e os pais e compreender as relações existenciais estabelecidas, já que boa parte do comportamento alimentar é aprendido.

Partindo destes pressupostos a pesquisa buscou compreender a percepção social da obesidade infantil através das narrativas das crianças e das famílias, considerando sua complexidade e inacabamento. Narrar alguma coisa consiste na "faculdade de intercambiar experiências", configurando-se naquilo que Eco chama de obra aberta, posição antecipada por Benjamin, na sua obra "O Narrador", (conforme citado por Dutra, 2002). 


\section{Metodologia}

\subsection{Delineamento do estudo}

O estudo foi realizado na perspectiva da pesquisa qualitativa fenomenológica que busca aprofundar-se na compreensão dos sentidos, das experiências vividas, aspirações, atitudes e na teoria da complexidade que aprofunda a dinâmica da coexistência e recursividade dos elementos envolvidos. O referencial teórico foi o da Fenomenologia Existencial de Heidegger (2002) que busca descrever o fenômeno tal como ele ocorre, compreendendo aquilo que se mostra e seus significados. A fenomenologia, redefinida por Heidegger têm como um dos seus pressupostos a máxima Hursseliana de "ir às coisas mesmas", isto é, como o sujeito vê, interpreta e vivencia determinada situação (Amatuzzi, 2009). Esta perspectiva tem sido considerada como um importante referencial nos estudos do campo da saúde, possibilitando que as pessoas e populações que vivenciam determinados fenômenos expressem seus sentimentos e significados em relação ao processo saúde-doença (Martins Savassi, Almeida \& Modena, 2012).

Entende-se que toda compreensão é parcial e inacabada, tanto a do nosso entrevistado, que tem um entendimento contingente e incompleto de sua vida e de seu mundo, como a dos pesquisadores, pois também somos limitados no que compreendemos e interpretamos (Minayo, 2012).

Sendo assim, para compreender a obesidade infantil a teoria da complexidade de Edgar Morin (1996) foi também evocada porque visa contrapor o paradigma da simplificação que se pauta por raciocínios lineares, a busca da não-contradição e a dicotomia entre ordem e desordem sem conceber estes conceitos como complementares e simultâneos. No entanto, não se trata de invalidar o paradigma clássico, mas sim de reconduzi-lo aos seus limites (Estrada, 2009). Já a fenomenologia busca compreender o fenômeno a partir dele mesmo. A atitude fenomenológica, na perspectiva complexa aponta uma opção pela multiplicidade de tendências filosóficas que dialogam entre si (Masini, 1989).

O pensamento complexo proposto por Morin (2007) oferece recursos para ultrapassarmos a lógica reducionista que pode ser uma das causas da ineficácia de alguns programas propostos para combater a obesidade infantil. Desconsiderar a subjetividade e a complexidade envolvida torna limitado o potencial de compreensão do tema. Algumas das ideias de Morin (2007) utilizadas para esta discussão são:

- Recursividade: Oposição ao princípio determinista da causalidade linear que acredita que todos os fenômenos têm uma causa e são, por isso explicáveis em relações particulares de causa-efeito; A é causa de B. É preciso pensar a recursividade ou, seja, a possibilidade de a causa agir sobre o efeito e de o efeito agir sobre a causa.

- Dialógica: Pensar dialogicamente é compreender que a realidade se constitui, modifica, destrói e regenera a partir de princípios e forças contrárias. Ordem e desordem não podem ser pensados separados, mas como um par que na sua relação dialógica produz as infinitas configurações e modificações do real.

É comum se atribuir causas lineares para explicar a obesidade; "engordou por causa da ansiedade", por exemplo. A recursividade nos remete a multicausalidade da obesidade infantil, que não é linear. A multicausalidade nos mostra que existe uma rede complexa atuando em que não é possível distinguir causa e efeito, pois o fenômeno representa ambos; engordou por causa da ansiedade, mas vemos que, por que engordou ficou ansioso e, além disto, as relações familiares, as pressões sociais e os estímulos midiáticos também vão influenciar no aparecimento da ansiedade e do engordar.

Ansiedade, então, é causa e consequência, ordem e desordem que compõe um quadro composto por vários elementos que não podem ser dissociados na tentativa de compreensão da obesidade infantil. Não existe obesidade isolada e não é possível tratar "a obesidade" de forma descontextualizada.

Devemos tentar compreender a vida da pessoa que apresenta este quadro vivencial no qual a obesidade é um dos componentes do Dasein. Parte-se da referência do outro como um ser-aí-no-mundo que seria o homem se relacionando com as coisas (instrumentos), com os outros (as demais presenças) e consigo mesmo. "Afirma-se isso tendo em vista que, ao ocupar-se, que é o principal e primeiro modo da presença se projetar, ela o faz em relação a estes três "momentos" (coisas, outros, e a si mesmo)", (Ferreira \& Ribeiro, 2007, p. 5).

Trata-se de ser capaz de pensar o real como um todo e não de o reduzir arbitrariamente fragmentando-o. Desta forma, a obesidade dever ser vista com todas as contradições, subjetividades, ordem e desordens que a compõe. Os pensamentos complexos junto com a atitude fenomenológica se constituem em um exercício que se mostra necessário para nos aproximarmos mais do fenômeno, não o fragmentando e enxergando o fenômeno tal qual ele se apresenta em cada ser-no-mundo.

Todos os participantes da pesquisa foram esclarecidos sobre os procedimentos da pesquisa e assinaram o Termo de Consentimento Livre e Esclarecido (TCLE). As crianças assinaram o termo de assentimento. Todo o padrão ético estabelecido pela comunidade cientifica foi respeitado. O projeto foi aprovado pelo comitê de ética sob o $\mathrm{n}^{\circ}$ CAAE: 47144615.8.0000.5091, submetido via plataforma Brasil em 14/07/2015.

\section{Procedimentos}

A pesquisa foi realizada no Hospital Infantil São Camilo. Trata-se de uma das principais instituições hospitalares infantis privadas de Belo Horizonte. A pesquisa foi realizada em grupos de intervenções multidisciplinares 
que são realizados no hospital semestralmente com famílias que vivenciam a obesidade infantil. Os grupos são quinzenais e possuem duração de 2 horas. A equipe é composta por nutricionista, pediatra e psicóloga. Foram 10 famílias participantes.

A idade das crianças foi estabelecida de acordo com o Estatuto da Criança e do Adolescente (ECA) que considera criança a pessoa até 12 anos de idade incompletos (Brasil, 1994). As crianças participantes se situavam na faixa etária de 9 a 12 anos (07 meninas e 03 meninos), de qualquer cor e situação econômica. Todas as crianças estavam acima do peso considerando a classificação proposta pelo IMC. As crianças já foram encaminhadas para o grupo com esta classificação aferida pelos médicos do hospital onde foi realizado o estudo. Os pais das crianças foram convidados sem distinção de idade, sexo, cor e situação econômica. Foi convidada a família, podendo participar todos que convivessem com a criança, pais, avós e outros familiares. Mesmo insistindo na importância dos pais e de outros familiares que moram com a criança estarem presentes houve adesão de apenas 3 pais. As mães das 10 crianças participantes foram assíduas aos encontros, totalizando 23 pessoas nos grupos.

Antes do início do grupo, os pais e as crianças foram convidados a narrar suas experiências, individualmente, acerca da obesidade infantil através das seguintes questões norteadoras: percepções em relação à obesidade, sentido da comida, limitações cotidianas e preconceitos sociais. As crianças realizaram técnicas gráficas para contar as suas vivências sobre os temas sugeridos, foi pedido a elas que desenhassem "como via comida em sua vida”, "como ela se via” e "como ela achava que os outros a viam". Com os pais foi realizada entrevista utilizando os três temas como mote para a narrativa.

Os grupos foram conduzidos pela equipe multidisciplinar com várias técnicas grupais, que abordaram temas relativos às vivências das famílias, comportamento e alimentação. Refletiu-se sobre a pressão da mídia, a “correria” do dia-a-dia, as dificuldades da reeducação alimentar e a afetividade que envolve a comida. Foram utilizadas colagens, rodas de conversa, jogos, entre outros.

Em todos os encontros as famílias eram convidadas a pensar sobre seus comportamentos e hábitos no cotidiano através de técnicas lúdicas e espaços para reflexões. A participação no grupo nos permitiu observar, interagir e compreender melhor o fenômeno da obesidade infantil e toda complexidade que o cerca.

\section{Análise dos dados}

As narrativas e as reuniões em grupo foram transcritas e identificadas através de códigos numerados por ordem de que foram entrevistados, preservando a identidade dos participantes. Para organização e análise dos dados, foi utilizada a Análise de Conteúdo (AC) de Bardin (1977), escolhida pela possibilidade de adequação às diversas condições de produção da palavra ocorridas na pesquisa. Construíram-se categorias temáticas conforme os temas que emergiram das narrativas. O objetivo foi, através da leitura cuidadosa e exaustiva, encontrar um conjunto de significados em comum, embora não se perca de vista a singularidade da vivência de cada um. Utilizou-se a AC enquanto ferramenta para organização temática das narrativas para posterior compreensão na perspectiva fenomenológica e complexa.

\section{Resultado e discussão}

De forma geral, as falas das crianças não se distanciaram muito das falas dos pais. Foi comum observar que algumas crianças, às vezes, utilizavam as mesmas expressões dos pais.

A partir da interpretação dos dados coletados, nas entrevistas e nos encontros no grupo, foram construídas cinco categorias temáticas: O significado da comida, a percepção social das pessoas acima do peso, a influência do sobrepeso infantil no cotidiano, a relação com profissionais da saúde e os motivos para a não adesão ao tratamento.

Este resultado possibilita a reflexão sobre a importância da escuta para as práticas de saúde. A criação de espaços intersubjetivos que valorizem a relação profissional de saúde e pacientes como parceiros da construção da saúde deve se pautar no comportamento dialógico, que, para Buber (1982), consiste em uma relação em que os membros se reconheçam para além da comunicação, buscando se compreender na busca pelo significado e pela interpretação das experiências vividas.

O cuidado nas práticas em saúde deve refletir "Uma atenção à saúde imediatamente interessada no sentido existencial da experiência do adoecimento, físico ou mental" (Ayres, 2004).

O cuidado que se revela nas práticas em saúde deve considerar a articulação da intervenção técnica com o sentido que esta tem para a pessoa. Tal articulação será possível a partir da escuta dos profissionais sobre o que as pessoas desejam como modo de vida. Assim, será possível adequar técnicas profissionais às demandas das crianças acima do peso e de suas famílias.

\section{Significado da comida}

Percebe-se nesta temática o significado da comida dividido em dois campos principais: prazer e necessidade. A percepção de pais e filhos foi análoga em alguns pontos. As crianças trouxeram aspectos negativos que os pais não colocaram de forma tão clara, "É o que engorda". Houve diferenças de nomenclatura também, pois enquanto os pais ser referem ao alimento como "necessidade", "imprescindível”, "o corpo pede” as crianças em sua maioria citaram como "fonte de energia" revelando um conteúdo provável nos bancos escolares e nas falas sociais. 
Um argumento bastante usado para fazer as crianças comerem é citá-lo como uma fonte de energia para conseguir fazer suas atividades. Já em relação ao alimento como prazer as expressões utilizadas foram "tudo de bom", "relaxa”, "gostoso", "prazeroso" entre outras.

O sentido de prazer atribuído a alimentação apareceu em falas associadas à preocupação com controle; "É muito bom comer, mas tem que controlar né?!” (EP1), "Sustenta a gente, mas não pode ser prioridade” (EP7), "Porque comida gostosa sempre é a que engorda?" (EP1). Percebe-se que prazer, necessidade e controle são instâncias conflitantes já que a liberdade existencial de realizar escolhas é cerceada pelas possibilidades e censuras sociais.

A comida enquanto "algo que relaxa" foi um significado atribuído ao ato de alimentar. A comida é colocada como uma solução para a tensão causada pela ansiedade, mas esta relação não é claramente percebida por muitos deles. É como se fossem elementos independentes um do outro. A necessidade de construir pontes relacionais entre os diversos elementos existenciais ficou evidenciada pelas percepções no grupo. "O problema do meu filho é ansiedade, ele engorda porque é ansioso" (EP9): neste tipo de afirmação nem sempre os pais percebem que o filho engorda porque fica ansioso e come demais, e há oferta alimentar excessiva, e quem compra o alimento calórico são eles, os pais, que provavelmente são ansiosos também e por isto o filho aprende este comportamento.

\section{Percepção social das pessoas acima do peso}

Entendendo a criança como um ser-no-mundo, ela afeta e é afetada por seu meio. Quando este mundo estabelece critérios excludentes de padrão social torna-se mais significativo à forma como são afetados.

Os pais relataram uma variedade de classificações atribuídas as pessoas acima do peso nas suas narrativas individuais e em grupo. Algumas foram: "relaxadas", "incapazes", "preguiçosas”, "não faz porque não quer” e "rejeitadas". Os profissionais da área da saúde ao considerar que a pessoa não praticou as orientações prescritas porque não quis, já que o "papel” profissional de informar foi realizado a contento, desconsideram os outros fatores envolvidos na questão e reforçam a visão estigmatizante de preguiça e relaxamento atribuído a estas pessoas. No grupo, foi comum ouvir frases sobre isto: "Dr. Fulana vai me xingar demais quando voltar a consultar porque não fiz o que ela mandou" (EP7). Oliveira (2008) em sua pesquisa relata situações semelhantes, nas quais profissionais na tentativa de sensibilizar os pais para a importância do tratamento do sobrepeso dos filhos, recorrem até mesmo a ameaças, insinuando a possibilidade de pedir a intervenção do conselho tutelar se eles não cumprirem as orientações.

Chega a ser perversa a expressão usada socialmente que é revestida como um incentivo “basta querer!”. Querer é um passo importante, mas não basta. Muitos outros elementos são necessários para implantar mudanças. E alguns não dependem unicamente da pessoa como, por exemplo, uma boa orientação profissional, condições ambientais para executar as mudanças, condições econômicas, emaranhados familiares que repercutem em conflitos psicológicos entre outros.

Percebe-se que muitas pessoas acima do peso utilizam argumentos como uma defesa antecipada aos preconceitos relatados. "Os outros acham que todas as pessoas gordas comem muito, eu como pouco" (EP4), "Tenho problema na tireóide por isto não emagreço” (EP10). Excetuando-se os casos de falta de compreensão, vê-se que a maioria tem acesso a informação que mostra que dificuldades hormonais não são suficientes para causar uma obesidade mórbida. Porém, insistir neste tipo de crença pode ser uma forma de amenizar e se defender de características sociais tão negativas como "preguiça”, "relaxada", "não faz porque não quer", entre outros.

No relato das crianças em relação a como acham que os outros a vêem foi frequente utilizarem eufemismos para a expressão "gorda”. Ficou nítido que a palavra "gorda (o)" representa um xingamento, uma ofensa. Assim afirmaram serem vistas como uma criança "um pouco gordinha (o)" (EC2, EC5, EC7, EC10), "uma menina forte" (EC8), "um menino grande” (EC6).

\section{Influência do sobrepeso infantil no cotidiano}

A única questão não abordada diretamente pelas crianças foi à disposição física. Os pais apontaram várias situações em que a criança se cansa muito rápido. Uma das mães relatou um episódio em que a filha participou de uma trilha ecológica e que o grupo tinha que diminuir o ritmo porque ela não conseguia caminhar na mesma rapidez que eles, o que causou constrangimento a criança.

A timidez e o preconceito social foram abordados de forma semelhante. Foram vários relatos de constrangimentos em situações públicas: não caber ou quebrar cadeira, pessoas rindo, apontando, utilizando vocabulário desrespeitoso para se referir a eles, entre outros. Percebe-se que os pais e os filhos, apesar de compartilharem percepções semelhantes sobre o preconceito sofrido, nem sempre possuem diálogo sobre isto, “(...) não sei como minha filha vê esta questão” (EP2).

A literatura mostra que crianças associam pessoas magras e gordas a qualidades negativas, enquanto indivíduos de tamanho mediano foram associados a qualidades positivas. Os extremos são considerados ruins. Desta forma, a criança interioriza muito cedo que ter excesso de peso é motivo de vergonha e embaraço. Tal percepção pode promover uma vivência depressiva por um baixo autoconceito e autoestima, levando ao seu isolamento social (Simões \& Meneses, 2007).

Os pais apontam também o preconceito sofrido por eles. Relatam a percepção de olhares que os culpabilizam pelo sobrepeso do filho, como uma falta de cuidado. 


\section{Relação com profissionais da saúde}

Das dez famílias entrevistadas, apenas uma não havia procurado, antes do grupo, algum profissional da saúde para intervir no sobrepeso do filho. Importante observar que era uma criança que estava ganhando peso há pouco tempo. Pode-se constatar que é frequente a procura pelo profissional para tratar sobrepeso e obesidade infantil. Necessário se faz situar o conceito de saúde em que se apoiou a pesquisa para compreender melhor esta temática.

A construção social do fenômeno da obesidade, com todos os interesses políticos, teóricos, econômicos, midiáticos e industriais envolvidos culmina na atual organização do conceito na área da saúde. Constata-se que em nossa sociedade predomina conceitos de saúde pela visão biomédica que determina obesidade como doença e a define por indicadores biológicos. Para exemplificar a limitação deste enfoque pode-se citar o Índice de Massa Corporal (IMC) que é um dos indicadores mais utilizados e apresenta inúmeras fragilidades, pois é importante que seus valores se correlacionem com outras medidas independentes de composição corporal, como percentual de gordura, medida antropométrica e nem sempre isto é feito (Cervi Franceschini \& Priore, 2005).

Neste modelo biomédico o profissional da saúde assume figura central e a intervenção é vertical, no qual ele assume o "saber" e a postura de que detém "o caminho" do tratamento, como se este fosse único. Assim, cobra e culpabiliza o usuário que por sua vez deposita no profissional a expectativa da solução dos seus problemas privilegiando a via medicamentosa e prescritiva, tão incentivada pela mídia e pela indústria farmacêutica. Desta forma, os profissionais da saúde se deparam com a falta de adesão ao tratamento, que os deixa perplexos e os pacientes e familiares se ressentem deles que os julga e recrimina. (Freitas, 2014).

Durante a realização do grupo percebeu-se sentimentos ambivalentes, ao mesmo tempo em que as pessoas ficam descrentes do tratamento, porque já foram em vários profissionais sem sucesso, elas se sentem "reféns" do profissional da saúde, pois entende que é o caminho mais seguro para reverter o quadro, a fonte mais confiável. Então atribuem a falta de sucesso ao fato de não ter "dado sorte de pegar" um profissional bom, "que resolva o problema". Alguns assumem sozinhos "a culpa", "Fui eu que não consegui seguir".

Este é outro aspecto que chama atenção, o raciocínio fragmentado, característico do paradigma clássico da simplificação abordado por Morin (2007). A busca de "culpados" é comum por parte dos usuários e dos profissionais. Trata-se de uma postura reducionista que torna improdutiva uma reflexão que deve abranger os elementos que atuam na questão de forma inter-relacional identificando motivações e não culpados.

Pode-se perceber nas narrativas o comportamento culpabilizado e a ineficácia de tratamentos apenas prescritivos através de falas como: "Pode falar que não come fruta aqui?" (EC3), "Posso falar de outras coisas que eu queira sem ser de alimentação saudável?" (EP6), "Devo ter umas 4 dietas lá em casa, de nutricionista e ele já foi ao endocrinologista também, mas é terrível, é muito difícil fazer, porque ele não tem pai, então eu saio para trabalhar e ele fica na casa do meu pai que não controla" (EP8). Daí a necessidade da compreensão do fenômeno no aqui-agora da pessoa que o vivencia muito mais do que generalizar e buscar explicações que se pretendam universais. Os pontos comuns das falas dos participantes propiciam elaborar questões e intervenções, porém sempre de forma inacabada, deixando espaço para o singular.

\section{Motivos para não adesão aos tratamentos}

Alguns dos motivos relatados pelos familiares para o não sucesso dos tratamentos anteriores foram:

- Trabalhar o dia todo e não controlar o que a criança come, já que quem toma conta dela não o faz.

- A não colaboração dos outros membros da família.

- A ansiedade do filho

- A compra de alimentos inadequados pela praticidade que eles oferecem

- A insistência da criança ao pedir alimentos

- Descontinuidade do tratamento pelo próprio usuário, pelo serviço de saúde ou ausência do profissional.

Durante a realização do grupo percebeu-se alguns motivos implícitos para a não adesão ao tratamento para emagrecer:

- A atitude de oferecer guloseimas como uma compensação pela ausência ou recompensa mais fácil de dar pelo bom comportamento da criança.

- A "dó" que se sente da criança ao ter que proibi-la de comer "as coisas gostosas" que ela quer.

- A pressão das outras pessoas que consomem o alimento, "Meu filho vai ficar vendo sem poder comer também?" (EP8).

- A ansiedade como um fator "acima” de toda prescrição.

Nos relatos dos familiares que atribuem a ansiedade como o principal impeditivo do emagrecimento da criança vê-se como ponto comum uma desresponsabilização familiar. Fala-se da ansiedade como se fosse algo fora do manejo da criança e da família, quase como uma "doença" que ele tem. E como doença precisa de intervenção externa. O auxilio profissional é valioso, porém o que se observa é uma excessiva carga atribuída a ele. Muitos familiares não percebem que a criança está em um meio onde ela aprende pela fala e pelo exemplo. Portanto, uma criança não fica ansiosa sozinha. É preciso considerar as relações familiares que podem construir uma ansiedade patológica que, provavelmente atinge todos. Além disto, a família, ao ter esta percepção pode rever hábitos e construir novos arranjos nas relações de modo a diminuir fatores que causam ansiedade. A procura pelo profissional 
deveria ser no intuito de contribuir para a constituição destas novas disposições.

Considerando o paradigma da complexidade é importante lembrar que a "não percepção" destes familiares acerca destas questões não é fortuita e que ela por si só é reveladora de emaranhados psicológicos que vão além da capacidade cognitiva de compreender e executar prescrições.

Tassara (2006) em sua pesquisa mostra que a vivência desofrimento dos familiares costuma se reeditar, veladamente, na relação com seus filhos, e nessa indiferenciação, as crianças sentem o sofrimento que faz parte das histórias dos familiares.

De acordo com a autora pode-se considerar que a expressão de passividade e de ansiedade, bem como o comer excessivo dessas crianças representa "a ponta de um iceberg em que a parte submersa representa o sofrimento delas amalgamado ao das mães, que tenta emergir e transparecer nos corpos obesos dessas crianças" (p. 44).

É importante citar outra observação feita nos grupos: todos os pais entrevistados estão ou já estiveram com sobrepeso. Duas mães do grupo realizaram cirurgia bariátrica. Mesmo assim é comum apontarem o sobrepeso do filho (a) como um problema isolado, como se a criança não quisesse comer direito e a "culpa" fosse dela e somente ela deve ser tratada. Nem sempre se relaciona ao sobrepeso o fato da alimentação ser comprada pelos pais e os primeiros hábitos serem ensinados por eles também.

Ampliar estas reflexões auxiliando os pais a compreenderem estas relações se mostra promissora para ocasionar mudanças conforme pôde ser observado no grupo. O auxílio que o profissional pode oferecer vai muito além de orientações. Rogers acredita que todo ser humano tem um potencial de crescimento pessoal inato e que ocorrerá desde que lhe sejam dadas as condições adequadas para tal. Seu pensamento enfoca o homem como uma totalidade, um organismo em processo de integração (LEITÃO, 1986). Desta forma, o profissional da saúde pode contribuir para propiciar estas condições para facilitar melhores escolhas, considerando as motivações implícitas e explicitas das pessoas.

\section{Conclusão}

As referências ao modelo biomédico que foca na doença e na responsabilização do indivíduo foram frequentes durante as narrativas. Entende-se que estas construções de sentido acerca da obesidade devem ser contextualizadas e compreendidas dentro da sua complexidade. Percebe-se que uma boa parte das pessoas ouvidas já possui informação suficiente do que "pode" ou não fazer em termos de alimentação e sobre hábitos que "deveriam ter" para emagrecer. Nas suas narrativas assinalam que nos serviços de saúde não há liberdade para comunicar as reais dificuldades, pois normalmente são censurados e até mesmos discriminados. Para a obesidade a prescrição é sempre a mesma: dieta, atividade física, remédio e cirurgia.
O profissional da saúde ao assumir a posição de que sabe o que é melhor para o usuário contribui para sua falta de autonomia e para o subdesenvolvimento do seu Dasein. Não é suficiente apenas transmitir orientações, é preciso se colocar como coadjuvante de um caminho que só a pessoa pode construir. Para isto é preciso ouvir e interagir com a realidade social e subjetiva da pessoa. A falta de perspectiva multidisciplinar também se constitui em um fator impeditivo para eficácia da prevenção e tratamento.

A teoria da complexidade e a perspectiva fenomenológica marcam que, mesmo que o profissional se especialize em uma única área, é fundamental que ele não perca de vista o diálogo com o "todo". Em um contexto de especializações, as ciências perdem a capacidade de comunicação entre si e os saberes que produzem não são agregados em visões globais dos fenômenos humanos.

As narrativas ouvidas pelas famílias participantes da pesquisa nos revelaram a complexidade dos fenômenos que envolvem a obesidade infantil. Os sentidos atribuídos às significações sociais acerca do comportamento alimentar são muitos. O corpo é visto de forma dissociada da mente ao se atribuir características de personalidade à pessoa obesa como se elas fossem todas iguais. A fenomenologia nos mostra o homem como um ser integral, não sendo possível fragmentá-lo e o pensamento complexo revela todo o universo de possibilidades e multicausalidade que existem em cada ser-no-mundo.

Portanto, para compreendera obesidade infantil e para se pensar em intervenções mais eficazes deve-se considerar o sentido atribuído à obesidade, as relações familiares, as condições socioeconômicas e todos os elementos que circundam o fenômeno. Deve-se ainda enfocar a pessoa e não a obesidade. A criança deve ser vista de forma integral e repleta de possibilidades existenciais, se lhe forem dadas condições adequadas para isto.

\section{Referências}

Abeso. (2015). Mapa da obesidade. Abeso. Disponível em: < http: //www.abeso.org.br/atitude-saudavel/mapa-obesidade>.

Ayres, J. R. C. M. (2004). O cuidado, os modos de ser (do) humano e as práticas de saúde. Saúde e Sociedade, 13(3), 16-29.

Amatuzzi, M. M. (2009). Psicologia Fenomenológica: uma aproximação teórica humanista. Estudos de Psicologia (Campinas); 26(1): 93-100.

Bardin, L. (1977). Análise de conteúdo. Lisboa: Edições 70.

Brasil. (1994). Estatuto da Criança e do Adolescente. Lei Federal $\mathrm{n}^{0}$ 8069, de 13 de julho de 1990. Índice elaborado por Edson Seda. Curitiba: Governo do Estado do Paraná.

Brasil. (2008). Pesquisa Nacional por Amostra de Domicílios. Ministério do Planejamento Orçamento e Gestão. Instituto Brasileiro de Geografia e Estatística - IBGE, 132. 
Buber, M. (1982). Do diálogo e do dialógico. São Paulo: Perspectiva.

Camargo, A. P. P. M.; Azevedo, B. A.; Antonio, M. A. R. M., et al. (2013). A não percepção da obesidade pode ser um obstáculo no papel das mães de cuidar de seus filhos. Ciência e Saúde Coletiva, 18(2): 323-333.

Cervi, A.; Franceschini, S. C. C.; Priore, S. E. (2005). Critical analysis of the use of the body mass index for the elderly. Revista de Nutrição, 18(6): 765-775.

Decastro, T. C.; Gomes, W. B. (2011). Aplicações do método fenomenológico à pesquisa em psicologia: tradições e tendências. Estudos de Psicologia, 28(2), 153-161.

Dutra, E. (2002). A narrativa como uma técnica de pesquisa fenomenológica. Estudos de Psicologia, 7(2), 371-378.

Estrada, A. A. (2009). Os fundamentos da teoria da complexidade em Edgar Morin. Akrópolis Umuarama, 17(2), 85-90.

Ferreira, G. P.; Ribeiro, G. M. F. (2007). O fenômeno do mundo em Heidegger. O fenômeno do mundo em Heidegger. "Existência e Arte"- Revista Eletrônica do Grupo PET - Ciências Humanas, Estética e Artes da Universidade Federal de São João Del-Rei - Ano III - Número III - janeiro a dezembro.

Freitas, F. C. (2014). A janela da escuta. Relato de experiência clinica. Belo Horizonte: Editora Scriptum.

Frontzek, L. G. M. (2016). Percepção dos pais sobre a obesidade dos filhos: revisão integrativa que apontou caminhos para a intervenção. Belo Horizonte. (No prelo, ainda não publicada).

Frontzek, L. G. M. (Org). (2015). Obesidades e psicologia. Porto alegre: Juruá.

Frontzek, L. G. M.; Fernandes, M. M.; Gomes, M. E. J. (2014). A multidisciplinary treatment for morbid obesity: Therapeutic experience with groups. Psychology, 5, 875-885.

Heidegger, M. (2002). Ser e tempo. Parte I. Tradução de Márcia Sá Cavalcante Schuback. 12. ed. São Paulo (SP): Vozes.

Leitão, V. M. (1986). Da teoria não-diretiva à abordagem centrada na pessoa: breve histórico. Revista de Psicología, 4(1): jan./jun. Fortaleza.

Martins, A. M.; Savassi, L. C. M.; Almeida, S. S. L.; Modena, C. M. (2012). Privação e padecimento: uma compreensão existencial do ser frente à Hanseníase. Hansen. Int., 37(1): 59-67.

Masini, E. (1989). O Enfoque Fenomenológico de Pesquisa em Educação. 1. ed. São Paulo, Cortez.

Melo, E. D.; Luft, V. C.; Meyer, F. (2003). Obesidade Infantil: como podemos ser eficazes. Jornal de Pediatria. Porto Alegre - Rio Grande do Sul, v. 80, n. 3, pág: 1 a 16, maio/junho.

Minayo, C. (2012). Análise qualitativa: teoria, passos e fidedignidade. Ciência \& Saúde Coletiva, 17(3): 621-626.

Morin, E. (1996). Ciência com consciência. Rio de Janeiro: Bertrand Brasil, 255p.

Morin, E. (2007). Introdução ao pensamento complexo. 3. ed. Porto Alegre: Sulina.
Nunes, M. A.; Appolinario J. C.; Abuchaim, A. L. G.; Coutinho W. (eds). (2006). Transtornos alimentares e obesidade. Porto Alegre: Artmed.

Savage, J. S.; Fisher, J. O.; Birch, L. L. (2007). Parental influence on eating behavior: conception to adolescente. JLME, 35(1), 22-34.

Oliveira, T. R. P. R. (2008). Abordagem da obesidade em adolescentes atendidos em serviço público de saúde: conceitos dificuldades e expectativas dos pacientes e seus familiares. Tese apresentada ao programa de pós graduação em ciências da saúde da faculdade de medicina. Belo Horizonte, UFMG.

Poulain, J. P. (2013). Sociologia da obesidade. São Paulo: Editora Senac.

Ribeiro, O. C. (2015). Criatividade na pesquisa acadêmica: método-caminho na perspectiva de uma fenomenologia complexa e transdisciplinar. NUPEAT-IESA-UFG, 5(1), 189-215. Artigo 89 Dossiê ECOTRANSD: Ecologia dos saberes e Transdisciplinaridade.

Simões, D.; Meneses, R. F. (2007). Auto -conceito em crianças com e sem obesidade. Psicologia: Reflexão e Crítica, 20(2), 246-251. Disponível em: <http://www.scielo.br/pdf/prc/ v20n2/a10v20n2.pdf >

Tassara, V. (2006). Obesidade na infância no contexto sociofamiliar: possibilidades de (des) construção e (res)significação de identidades (pré) escritas. Programa de pós-graduação em ciência da saúde - UFMG. Disponível em: www.bibliotecadigital.ufmg.br/>.

Who. (1998). Preventing and managing the global epidemic. Report of a WHO consultation on obesity. Geneva: World Health Organization.

Luciana Gaudio Martins Frontzek - Doutora em Saúde Coletiva pela Fiocruz - BH, Mestre em psicologia social pela UFMG. Foi coordenadora dos grupos de promoção da saúde e da equipe de psicologia da- Vitallis Saúde SA. Foi colaboradora terceirizada da equipe multidisciplinar da ANS (Agencia Nacional da Saúde), ambos em Belo Horizonte. Atuante em psicologia clínica e na docência. Centro de Pesquisas René Rachou-Fiocruz, Belo Horizonte, Minas. Av. Augusto de Lima, 1715. 30190-002. Tel. (31) 3493-6891/98862-3112. E-mial: lucianagaudio@yahoo.com.br

Luana Rodrigues Bernardes - Graduanda de Psicologia pela Universidade Salgado de Oliveira em Belo Horizonte. Atua como bolsista de inicíação científica pelo Conselho Nacional de Pesquisa (CNPq), no Centro de Pesquisas René Rachou (CPqRR) da Fundação Oswaldo Cruz (Fiocruz Minas). Universidade Salgado de Oliveira - Belo Horizonte.

Celina Maria Modena - Psicóloga (Universidade Federal de Minas Gerais), com Pós-Doutorado em Saúde Coletiva pela Fundação Oswaldo Cruz (Fiocruz). Docente do Programa de Pós-Graduação em Saúde Coletiva do Centro de Pesquisas René Rachou (CPqRR) da Fundação Oswaldo Cruz (Fiocruz Minas) e Vice-Líder do Grupo de Pesquisas em Políticas Públicas e Direitos Humanos da Fiocruz Minas. Centro de Pesquisas René Rachou-Fiocruz, Belo Horizonte, Minas Gerais.

Recebido em 12.07.16 Primeira decisão editorial em 30.09.16 Segunda decisão editorial 01.03.2017 Aceito em 15.03.17 